- 18. Stephenson.- "A case of acne rosacea of the cornea." Trans. O.S. of the U.K., Vol. XXVI, p. 47.

19. Stephenson and Jamieson. - " A note upon phlyctenular affections of the eye." Brit. Med. Jl., April, 16, 1910.

20. Straub--"An ophthalmological contribution to the doctrine of scrofulosis." Address before the Oxford Ophthalmological Congress delivered on July 18, 1912. The Ophthalmescope, Vol. X, p. 618 .

21. Straub. - "Scrofulosis and dormant tuberculosis." Geneeskundige Bladen, No. I, Ig05.

22 Weekers._- The pathological anatomy of ocular phlyctenulae." Académie de Méd. de Belgique, June 25, 1910.

\title{
PHLYCTENULAR DISEASE AND ITS RELATION TO TUBERCULOSIS
}

\author{
BY
}

R. Beatson HiRd, M.D., F.R.C.S.Ed., CaPt. R.A.M.C. (T.)

HON. OPHTHALMIC SURGEON TO THE GENERAL HOSPITAL, BIRMINGHAM ; HON. ASSISTANT SURGEON TO THE BIRMINGHAM EYE HOSPITAL.

THE substance of my present remarks on the relationship of tuberculosis to phlyctenular disease formed the subject of a short paper read before the Midland Medical Society in April, 1914. I have purposely delayed its publication in order that the cases might be kept under observation for some time to see if the results were satisfactory. The number of cases dealt with is not large, but I have had scores since then and have had no reason to change my opinion of four years ago. Much has been written on this subject during the last few years, and I offer this contribution to confirm and strengthen the growing opinion that there is a relationship between phlyctenular disease and tuberculosis. If this is correct, then phlyctenular disease assumes an importance beyond that of a superficial local inflammation. It is undoubtedly the commonest cause of corneal opacities in children. During the last four years as ophthalmic surgeon to the City of Birmingham Education Committee, I have had 4,702 new cases of children suffering from ocular defects referred to me, and amongst these, 308, or over six per cent., had corneal scars in one or both eyes. Many in consequence have had to be educated at one of the special schools for the partially-blind and blind. The children in these schools are frequently leaving or being transferred to other schools, but the following was the result of an examination of all the scholars attending one of the schools for the partially-blind inspected by me a little while ago. I found no less than 64 per cent. suffering from corneal opacities which had rendered their education there a necessity. The commonest cause was phlyctenular keratitis which accounted for 50 per cent. for certain. There were some doubtful cases which might well have come into this group, but I excluded 
them as the history was uncertain. This damage done to vision is a very serious matter, often the sight being so crippled that the child will never be able to be a useful citizen. In its active state the disease prevents the child from attending school often for months, so that the child falls behind in education even if the sight is not affected sufficiently to render it necessary to give up ordinary school. The ravages of this disease amongst the children of the poorer classes is a tragic chapter in their little lives, and taxes the patience of both parents and doctor. Its importance, then, needs no further emphasis. It is absolutely essential that these children should receive sympathetic care and early efficient treatment before the disease has become firmly established and before permanent damage is done to the sight. Any treatment that will hasten the cure and above all prevent recurrences should be tried and persevered with. I am firmly convinced, from my own experience of the past few years, that in tuberculin we have a very important remedy. In this I am in full agreement with many other workers in the same field.

The remarks which I have to make relate to fifty-seven consecutive cases of phlyctenular disease attending my department at the General Hospital, Birmingham. There was therefore no selection of cases whatever. The time covered was a period of about fifteen months. The series of cases would have been extended considerably but for the present war. My own military service and that of my colleagues made such a call on our time that thorough investigation, such as I wished to continue, had to be given up.

I have purposely left untouched the large number of cases under my care at the Birmingham Eye Hospital, because I had not the ready facilities there for the necessary investigations. All my cases were examined from the point of view of tuberculosis as a causal agent, at the same time bearing in mind other factors held responsible for this disease.

For the diagnosis of the presence of tuberculosis, I made use of the following:

(1) The general appearance of the patient. The majority presented the typical appearance which has been designated strumous, especially the torpid variety.

(2) Family history of tuberculosis.

(3) The presence of definite tuberculous lesions elsewhere in the body, including those disclosed by X-ray examinations of the chest.

(4) Tuberculin tests. I used the cutaneous test of von Pirquet, and also subcutaneous injections of tuberculin.

The analysis of my 57 cases presented the following results :--

(1) Types of disease.-(a) Conjunctivitis. In 34 of the cases the conjunctiva was affected, giving a percentage of $59^{*} 6$. This included all varieties of the disease, from fine multiple sand-like 
deposits at the limbus to the large florid nodules. Of this latter type there were six cases, and in four of them active turberculosis elsewhere in the body was demonstrated, and in one other case the mother of the child was consumptive. It would be interesting to know if this variation has anything to do with the strain of tuberculosis, bovine or human. I was unable to come to any definite conclusion.

(b) Keratitis. The cornea was affected in 41 of the cases, giving a percentage of $71^{\circ} 9$. This group included fine superficial lesions with loss of surface, as well as definite ulcers, in a few cases large and deep. There were 13 cases of pronounced ulceration. These ulcers were persistent and reluctant to heal. In one case of a deep central ulcer, no progress took place for weeks under ordinary local treatment, but was soon cured with tuberculin injections.

In 17 of the cases the conjunctiva and cornea were affected at the same time.

(c) Blepharitis. In 6 of the cases there was a chronic form of blepharitis, with in some instances considerable general thickening of the lid. This is a special type of blepharitis which resists ordinary lncal treatment, but which can be cured by tuberculin injections. The percentage of these cases was $10 \cdot 5$. I have recently had a marked example of this blepharitis under my care, which cleared up in a few weeks under tuberculin without any local applications.

(2) Sex.-The cases were very evenly divided between the two sexes, as there were 26 males and 31 females.

(3) Age.-The age incidence is shown in the accompanying chart. It is interesting to note that 87.7 per cent. of the cases occurred during the age period from 1 to 15 , and that no cases were met with after the age of 25 . Indeed, with very few exceptions, phlyctenular disease is an affection essentially of childhood. Several explanations have been forthcoming. Harman has blamed the decay of the teeth. A possible explanation seems to me to be the infection in early childhood from milk, with an evident increase either in immunity or resistance as the child grows up. If the condition is tuberculous, the milk is one of the most likely origins of infection and may account for the relative frequency amongst the poorer classes. I have had a few undoubted cases amongst apparently healthy country dwellers; in every case there was a tuberculin reaction, and the milk was the only possible source of infection. I wish I could have known the condition of the cows from which the milk was obtained. If the milk is the chief source of infection, then the bovine strain should be the usual cause, and this must be remembered when treating with the tuberculin. If human tuberculin is used without success the bovine variety should certainly be given a trial. 
(4) The Eyes affected.-In 33 cases both eyes were affected. In 11 the right eye only, and in 10 the left only. In three instances the side affected was not recorded.

Chart Showing age INCIDENCE in 57 CASES OF Phlyctenular Disease.

Age in years.

\begin{tabular}{|c|c|c|c|c|c|c|c|c|c|c|c|c|c|c|c|c|c|c|c|c|c|c|c|c|c|}
\hline & & & & & & & & & & & & & & & & & & & & & & & & & \\
\hline Nos. & 1 & 2 & 3 & 4 & 5 & 6 & 7 & 8 & 9 & 10 & 11 & 12 & 13 & 14 & 15 & 16 & 171 & \begin{tabular}{l|l}
18 & 1
\end{tabular} & 192 & 202 & 212 & \begin{tabular}{l|l|l}
22 & 2
\end{tabular} & 324 & 25 & 26 \\
\hline 14 & & & & & & & & & & & & & & & & & & & & & & & & & \\
\hline 13 & & & & & & & & & & & & & & & & & & & & & & & & & \\
\hline 12 & & & & & & & & & & & & & & & & & & & & & & & & & \\
\hline 11 & & & & & & & & & & & & & & & & & & & & & & & & & \\
\hline 10 & & & & & & & & & & & & & & & & & & & & & & & & & \\
\hline 9 & & & & & & & & & & & & & & & & & & & & & & & & & \\
\hline 8 & & & & & & & & & & & & & & & & & & & & & & & & & \\
\hline 7 & & & & & & & & & & & & & & & & & & & & & & & & & \\
\hline 6 & & & & & & & & & & & & & & & & & & & & & & & & & \\
\hline 5 & & & & & & & & & & & & & & & & & & & & & & & & & \\
\hline 4 & & & & & & & & & & & & & & & & & & & & & & & & & \\
\hline 3 & & & & & & & & & & & & & & & $\lambda$ & & & & & & & & & & \\
\hline 2 & & & & & & & & & $\sqrt{1}$ & & & & & L & & & & & & & & & & & \\
\hline 1 & & & & & & & & & & & & & & & & & & & & & & & & & \\
\hline 0 & & & & & & & & & & & & & & & & & 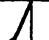 & & & & & & & & \\
\hline & & & & & & & & & & & & & & & & & & & & & & & & & \\
\hline
\end{tabular}

(5) The Teeth.-The teeth were carefully examined in 32 of the cases. No decay whatever was present in 17 , or over 50 per cent. It is a fact that the teeth tend to decay in the strumous children rather readily, and I, personally, do not attach any importance to the teeth as a causal agent in this disease. My figures, I think, substantiate this. One obstinate case with frequent recurrences sought advice elsewhere and the cause was attributed to one decayed tooth, but expert dental treatment failed to prevent further recurrences and I have the patient now undergoing a course of tuberculin. A positive reaction was obtained in this patient with focal reactions in the affected eye after tuberculin injection.

(6) Cervical Adenitis.-Enlargement of the cervical glands was recorded in 36 cases, or 63.1 per cent. Some of these may have been due to infection through the teeth. I am of opinion that a large number were undoubtedly tuberculous. In three cases the 
glands softened and went on to abscess formation, requiring surgical interference.

(7) Evidence of tuberculosis elsewhere in the body.-In 30 of $\mathrm{my}$ cases, or 52.6 per cent. of the total, a careful search was made for tuberculosis elsewhere in the body, and I am much indebted to my medical and surgical colleagues at the General Hospital for their assistance. In these 30 cases tuberculous lesions were found in 23 , or $76^{\circ} 6$ per cent., of the cases examined specially, and 40.3 per cent. of the total of my series. The cases particularly chosen for the examination were those which I wished to treat with tuberculin on account of their chronicity, severity, or reluctance to get well under ordinary treatment, and were especially the corneal ones. The sites of the tuberculous lesions were as follows:

(a) Cervical glands.-I mention here the three cases which went on to abscess formation requiring surgical aid. There were several also which did not go on to abscess formation, but in which the glands were excised and pronounced tuberculous.

(b) Lesions in the lungs were found in 12 cases, and in one other case there were some signs, but not very definite. These cases included old healed apical disease, enlarged bronchial glands shown by X-ray photograph, and in one there was definite active tuberculosis at the apex.

(c) Lupus of the face was present in three cases. There was also one case of scrofuloderma of the neck.

(d) Joint disease was present in four cases and pronounced by the surgeon in charge as tuberculous. The joints affected were shoulder 1 , wrist 1 , hip 1 , and knee 1 .

(e) Bone disease. There was 1 instance of tuberculous tarsitis. In 7 of the cases especially examined for tuberculosis we were unable to find any signs of that disease elsewhere.

(8) Tuberculin tests were performed in 16 cases where the diagnosis was in doubt. In 15 , or 94.1 per cent., the result was positive. One case which did not give a positive reaction was pronounced by the physician examining the case as showing undoubted physical signs in the lungs. In this case the test was von 'Pirquet's cutaneous test. In 6 other cases in which this test was done the result was positive. The great majority of cases of phlyctenular disease give a positive von Pirquet, as I have found at the Birmingham Eye Hospital, where I almost always have this test done. A few cases fail to give it, although they are clinically exactly similar to the other ones. In 9 of my cases the subcutaneous injection of tuberculin was employed, and in all a positive reaction was obtained.

(9) Tuberculin treatment.- I was not permitted to carry this out in every case I wished, but a course of tuberculin was given in 14 cases with excellent results in 12 , or 85.7 per cent. It 
is interesting as well as gratifying to record that in 2 cases only has there been a recurrence to my knowledge, and in both cases I gave a further course of tuberculin and they have since remained well. From two to three years have now elapsed since these cases were treated. Tuberculin was not the sole treatment given in any case. The usual local remedies, such as yellow oxide of mercury ointment, atropin, dionin, etc., were used, and in a number of cases cod liver oil in some form was supplied. The children were also encouraged to get out in the fresh air as much as possible. There are a few cases I should like to refer to in particular.

One case (26) was a boy, aged 12, who had a consumptive mother. He had been troubled with his eyes for months, and had not attended school for a very long period. He had the florid type of phlyctenular conjunctivitis, and was always getting recurrences. He had swollen cervical glands and gave a positive tuberculin test. I tried this boy on all the ordinary remedies for some weeks without any good result. $\mathrm{He}$ soon mended under tuberculin injections, but left off attending before his course was completed. He came back to me sometime later with a recurrence and had further tuberculin, attending regularly. Since then there has been no further recurrence.

Perhaps the most interesting were two sisters, Nellie (113), aged 12, and Lily (196), aged $5 \frac{1}{2}$. The elder sister attended hospital two months before the younger. Both her eyes were aftected, the cornea and conjunctiva being attacked. She was typically strumous in appearance, had enlarged cervical glands, and definite evidence of lung tuberculosis. She gave a positive tuberculin reaction. For three months she was given all the usual treatment, but was never well enough to attend school. She suffered from intense photophobia and lacrymation, had the type of blepharitis referred to above, and developed a deep central ulcer which absolutely stood still under all the treatment tried. After two months she arrived one morning with her younger sister, Lily. This child was also typically strumous, and suffered from blepharitis and phlyctenular conjunctivitis and corneal ulcers. She had enlarged cervical glands and signs of lung tuberculosis. She was also put on ordinary recognized treatment. When she had been attending a month with no definite improvement, and her elder sister three months, I decided to give the elder sister tuberculin. The effect was really remarkable. The chronic ulcer began to heal straight away, and the whole condition to improve. She began to get colour in her pale cheeks, and was able to open her eyes properly. She left her little sister standing. After several weeks I started the younger sister on tuberculin also, as she had not moved at all in the meanwhile. Her lacrymation, blepharospasm, etc., also began to clear up. Both these children had been absent from school for several 
months, but they soon got well enough to return. The elder girl's vision when she had completed treatment, was right eye 6/12 part and left eye 6/18. The cases of these two children would alone have convinced me of the value of tuberculin. I have had numbers since then equally convincing. I would just refer to another case supporting this statement:

A.M., a woman, aged 20. She had lived in the country all her life on her father's farm, and managed the dairy, including milking the cows. From the age of 14 she had suffered from inflammation of both eyes with only short intervals free from the trouble. It was a great distress to her and much interfered with her work. She had sought advice elsewhere, but had never had more than temporary relief. When I saw her she had scars on both corneæ and some fine loss of corneal epithelium in one eye. There was much photophobia and lacrymation. She was a healthy, stoutly built girl. A von Pirquet test was markedly positive and the results took over eight weeks to subside. Local treatment was tried for a few weeks with but moderate success, and I persuaded her to have a course of tuberculin. This course lasted five months. There was a local reaction after almost every injection and several focal reactions in the eye of a mild, but definite, nature. She madegradualand steady progress. After starting the tuberculin she was soon able to do her work, and there were no fresh corneal ulcers. When the course of treatment was finished her vision was right eye $6 / 6$ and left eye $6 / 6$ part with glasses correcting some astigmatism. It is now over a year since she finished her treatment with tuberculin, and with the exception of two days when she had slight irritation in one eye, 10 months ago, she has been absolutely free from any ocular trouble, a thing she had not known for several years. There is no object in detailing more cases. Those I have cited are typical. One thing that has impressed me is that the corneal opacities seem to clear up better when tuberculin is used. It is true that I gave all these patients local treatment, such as yellow oxide of mercury ointment, often combined with dionin, applied continuously for a month. I always have a number of these cases undergoing tuberculin treatment at hospital. Now and again I get a very obstinate case, and I am sure in some of these, at any rate, there is a syphilitic taint as well, for the Wassermann test is positive as well as the tuberculin test. In such cases both stigmata will require appropriate therapeutic attention.

Just a few remarks on the use of tuberculin. von Pirquet's cutaneous test will be found to give rise to reactions of varying intensity and, I think, may be used as an index to the sensitiveness of the patient to tuberculin and guide one as to the strength of the initial dose to be selected in starting the treatment. It must be a matter of common observation that there is often a favourable turn in the local disease after this cutaneous test. It is, of course, 
only transient and due to absorption of some of the tuberculin at the site of the test, and may be taken as an encouraging sign for further tuberculin treatment. I make use of both T.R. and B.E. preparations, generally prepared from the human strain, but in some cases the bovine. The T.R. being the weaker preparation it is better to begin with it in cases believed to be rather sensitive. It may afterwards, if necessary, be followed up with a course of B.E. When using T.R. my initial dose is never more than $1 / 10,000 \mathrm{mg}$. If there is no focal reaction I gradually increase the dose every four 'days until 1/1,000 mg. has been given, when I give the injections once a week, increasing up to $1 / 100 \mathrm{mg}$. After that I give this dose, or $1 / 50 \mathrm{mg}$., repeated a few times once a fortnight. When using B.E. I start with 1/100,000 mg., or sometimes even less, and give it in increasing doses on a similar scale to the T.R. Each case, however, must be treated on its own merits, and no procedure can be laid down applicable to every case. Opinions, I know, differ as to the variety of tuberculin to be used and its dosage. Chacun à son goût. The method I have used has given me every satisfaction.

For over the past ten years now, evidence has been steadily accumulating in favour of the relationship of tuberculosis to so-called phlyctenular disease, and yet it is not universally accepted, or, if it is, then this disease does not always receive the attention it should. Hundreds of cases are treated in a more or less perfunctory manner, and having seen the results of the ravages of this disease amongst thousands of children attending the schools in a large - city, one hopes that the time has arrived when everything possible will be done to stop it. As far back as 1906 Nias and Paton ${ }^{1}$ examined the opsonic index for tubercle in a number of cases of phlyctenular disease. They found the blood behaved in a manner quite typical of a definite tuberculous infection, and concluded that the disease was due to attenuated or dead bacilli escaping from some focus, identified or not. Since then there have been numerous publications on the subject. I would particularly call attention to the discussion on this subject at the annual meeting of the British Medical Association in $1912^{2}$, so ably opened by George Mackay. His paper, and those that followed, determined me to settle the question so far as my cases were concerned. Contributions on this subject have been made by Stephenson ${ }^{3}$, Weekers ${ }^{4}$, Davis and Vaughan ${ }^{5}$, to mention only a few. They have all supported the tuberculous cause of this disease. Parsons ${ }^{6}$ holds that the disease is not an eczema; that staphylococci found may be accessory though not causal, but more likely are mere contaminations. He mentions the possibility that the disease is due to tubercle toxins. Tubercle bacilli have never been demonstrated in the tissues affected and inoculation experiments have proved negative. The disease then must be due either to toxins or bacillary remains or fragments conveyed either 
viâ the blood or lymph. As the cornea is normally avascular the lymph spaces would appear to be the only road of infèction for that tissue. The disease, however, appears primarily to affect what is morphologically the conjunctival portion of the cornea, extending deeper beneath Bowman's membrane later. Iwanoff has shown it to be an infiltration round the nerves, and this may account for the pain and photophobia. This photophobia and reflex spasm of the lids are characteristic signs of this disease and have always seemed to me to have a direct connection with involvement of the fifth nerve terminations. Is it possible that in these cases the fifth nerve is hypersensitive to tubercle toxin, if not actually acted upon by it? In such a case the disease may have some pathological relationship to herpes.

\section{REFERENCES.}

1. Nias and Paton. - Trans. Ophthal. Soc, of the United Kingdom, I906.

2. British Medical Jl., Oct. I9, I9I2.

3. Stephenson.-British Medical Association, 1910.

4. Weekers. -Ophthalmoscope, Vol. IX, 653 .

5. Davis and Vaughan.-Ophthalmic Record, Sept., 1912.

6. Parsons. - Pathology of the Eye, Vol. I, p. 76.

\section{THE USE OF TUBERCULIN IN EYE DISEASES}

BY

Fr. VERHEYdEN, M.D. Louvain.

LATE CHIEF ASSISTANT TO THE EYE DEPARTMENT, POLYCLINIC, BRUSSELS; TEMPORARY ASSISTANT SURGEON TO THE EYE, EAR, AND THROAT HOSPITAL, SHREWSBURY.

My object is to lay before my readers, and to sum up briefly, the results of nearly three years' experiments, partly by Drs. C. G. Russ Wood and F. A. Anderson, and partly by myself, of the continued and systematic use of tuberculin in a number of eye diseases.

Cases of "strumous" affections, such as keratitis strumosa, keratoconjunctivitis, miliary keratitis, tuberculous iritis, irido-cyclitis, episcleritis, scleritis, central tuberculous choroiditis, and tuberculous paralysis of the third nerve, were at different times submitted to the treatment.

\section{Keratitis strumosa in its various manifestations}

All used to hospital ophthalmic work, know how disappointing may be the treatment of the above-named disease. These forms of localized tuberculosis common in children are an ideal field for tuberculin treatment in small doses. The treatment is best given in hospital, because definite and precise precautions should be taken to spare the patients avoidable inconveniences. This disease, so 